\title{
Epidemiology of fragile skin: Internet-based surveys in Mexico and Russia
}

Jorge Ocampo-Candiani'

Nikolay Murashkin²

Asmaa Zkik ${ }^{3}$

Markéta Saint Aroman ${ }^{4}$

Pierre Wolkenstein ${ }^{5}$

'Dermatology Department, Hospital Universitario Dr Jose Eleuterio Gonzalez, Universidad Autonoma de Nuevo Leon, Nuevo León, Mexico; ${ }^{2}$ Dermatology Department, Federal State Autonomous Institution, Scientific Center of Children's Health of the Ministry of Health of the Russian Federation, Moscow, Russia; ${ }^{3}$ Pierre Fabre S.A., Boulogne Billancourt, ${ }^{4}$ Laboratoires A-DERMA Pierre Fabre Dermo-Cosmétique, Lavaur, ${ }^{5}$ Department of Cancer, Immunity, Transplantation and Infections, Hôpital Henri Mondor (APHP), University Paris Est Créteil, Créteil, France
This article was published in the following Dove Press journal:

Clinical, Cosmetic and Investigational Dermatology

10 June 2017

Number of times this article has been viewed

Background: Fragile skin is a poorly understood skin condition, particularly in the general adult population. There are currently limited epidemiological data on the prevalence of fragile skin in adults. The objectives of this study were to assess the prevalence of perceived fragile skin across different skin types in representative samples of the general adult populations in Mexico and Russia, and to identify skin characteristics associated with perceived fragile skin. Methods: Two identical cross-sectional surveys, using a short online self-administered questionnaire, were conducted on samples of recruited individuals that were representative of the general Mexican and Russian populations. Participants responded to questions about fragile skin, with the main question being "In your opinion, do you have fragile skin (ie, skin less resistant and reacting quickly to external aggressions)?”. The survey also covered questions relating to skin appearance, skin symptoms, skin disease, dermatological procedures, and living environment and climate.

Results: Overall, 1,210 individuals in Mexico ( $\mathrm{N}=606)$ and Russia $(\mathrm{N}=604)$ completed the online survey. Fragile skin was perceived in $50.0 \%$ and $45.9 \%$ of participants in Mexico and Russia, respectively. The principal skin appearance characteristics reported by individuals with perceived fragile skin were thin, easily wrinkled, and transparent; the main skin symptoms were dryness, redness, and/or itching ( $\geq 50 \%$ of individuals in Mexico), and dryness, tightness, and/ or redness ( $>60 \%$ of individuals in Russia). Individuals with perceived fragile skin had experienced skin disease and/or undergone a dermatological procedure in the past 12 months, and they reported being exposed to stress ( $>80 \%$ of individuals in both surveys).

Conclusion: A substantial proportion of the general adult population of Mexico and Russia perceived that they had fragile skin, regardless of their skin type; fragile skin was perceived more frequently in women. These findings should assist dermatologists to extend their understanding and management of individuals with perceived fragile skin.

Keywords: epidemiology, fragile skin, prevalence, skin type, survey

\section{Introduction}

The skin, the largest human organ, represents an interface between the body and the environment. The most important function of skin is the formation of an effective barrier, providing protection from pathogen invasion and repelling environmental assaults, as well as preventing the unregulated loss of water and solutes. ${ }^{1,2}$

Physical disruption of the skin may be inborn or acquired, and the structural and regulatory factors involved can be present from the dermis to the stratum corneum, frequently resulting from defective structural proteins or a faulty mechanism leading to abnormal protein expression and/or function. ${ }^{3}$ 
The concept of fragile skin covers a wide spectrum of skin conditions, including subjectively perceived states of skin reactivity resulting from environmental insults. On the basis of constitutional factors relating to the structure and function of the epidermal barrier, the concept of fragile skin can be a subjective (experienced) and/or objective (clinically evaluated) perception of the skin's condition. ${ }^{4}$

Fragile skin can be classified into four categories: constitutional (physiological), circumstantial (environmental), pathological (related to dermatoses), and iatrogenic (related to dermatological acts and topical dermatological treatments). ${ }^{3}$

For constitutional (physiological age, localization) fragile skin, it is well documented that the epidermis is fragile in specific populations, including newborns, children, adolescents, and the elderly. ${ }^{4,5}$ For example, compared with adult skin, newborn skin is structurally and functionally immature and, throughout at least the first year after the birth of a newborn, the skin undergoes physiological maturation. ${ }^{6}$

With regard to circumstantial (environmental) fragile skin, it is important not to overlook the potential influence of environmental aggression (eg, rapid temperature changes, ambient humidity, and sun exposure), psychological stress, and aspects of everyday life (eg, adolescence, unemployment, and family problems). ${ }^{3}$ There is a growing body of evidence regarding the underlying pathophysiological mechanisms by which psychosocial stress influences skin homeostasis. ${ }^{7}$ All these factors may overlap with the objective signs of skin "fragility," impacting self-perception in individuals and affecting the perception of fragile skin. ${ }^{3}$

The third category of fragile skin, pathological fragile skin, is associated with a wide range of skin diseases, including atopic dermatitis, psoriasis, acne, rosacea, and contact dermatitis. ${ }^{3,8}$

Iatrogenic fragile skin is related to iatrogenic origin dermatological procedures (eg, laser, peelings, and dermabrasion) and topical treatments, such as irritating local anti-acne treatments (eg, retinoids). ${ }^{3}$

Currently, with the exception of a telephone-based survey in almost 5,000 individuals from France, Japan, Spain, Sweden, and the USA, ${ }^{9}$ there are limited epidemiologic data on the prevalence of perceived fragile skin and skin characteristics associated with perceived fragile skin in different general adult populations.

The objectives of the current study were to assess the prevalence of perceived fragile skin in the general adult populations of two countries with very different populations, climates, and lifestyles (Mexico and Russia), and to identify skin characteristics associated with perceived fragile skin.

\section{Methods}

\section{Study design and setting}

Two identical cross-sectional surveys, using a short online self-administered questionnaire, were conducted in Mexico and Russia (between October 16 and 28, 2015). Consumer Science \& Analytics (CSA, Puteaux, France) conducted each survey on samples of $\sim 600$ recruited individuals who were representative of the general Mexican and Russian populations.

\section{Study participants}

Participants were selected from an Internet access panel established by CSA, composed of 89,000 and 190,000 individuals from Mexico and Russia, respectively. All recruited individuals were aged $\geq 18$ years. Since the study consisted of two identical surveys and did not include manipulation of the subject or the subject's environment, institutional review board approval was not necessary.

Participants were invited by email to participate in the surveys and selected according to the national quota method (gender, age, and geographical region). At their recruitment, each participant agreed to the country-specific Terms and Conditions and Privacy Policy in order to utilize their data.

\section{Data collection}

Responses from each participant were collected online and captured directly in the database for analysis. Data were deidentified and have been transferred to Pierre Fabre. Participants responded to questions about "fragile skin," with the main question being "In your opinion, do you have fragile skin (ie, skin less resistant and reacting quickly to external aggressions)?". In addition, the survey covered a series of other questions, relating to skin appearance (eg, transparent, thin, easily wrinkled, and velvety in appearance), skin symptoms (tingling, warming up sensation, tightness, itching, burning, pain, redness, and dryness), skin disease (eg, acne, eczema, psoriasis, and pigment spots), dermatological procedures (eg, peeling, lasers, dermabrasion, dermatological surgery, and wrinkle filling), and living environment and climate (eg, sun, wind, cold, pollution, humidity, air conditioning, and stress). Medical history and socioeconomic data were also recorded.

\section{Statistical analysis}

Quantitative variables are described by the mean, median, standard deviation, minimum, and maximum, and were compared using the Student's $t$-test or Wilcoxon rank sum test. Qualitative variables are described by the frequency and percentage, and were compared using the $\chi^{2}$ test, or Fisher's 
exact test if conditions for application were not met. Descriptive analyses were performed on the overall populations and by gender, age category (18-34, 35-44, and $\geq 45$ years), and perceived fragile skin. The level of significance was set at 0.05 . There were no missing values because only participants with a complete questionnaire were analyzed. Statistical analyses were performed using SAS software (version 9.4; SAS Institute, Cary, NC, USA).

\section{Results}

A total of 1,210 individuals in Mexico ( $=606)$ and Russia $(\mathrm{N}=604)$ completed the online survey. Table 1 presents demographic data for all participants by country of origin.

\section{Mexico}

Among the 606 participants in Mexico, 51.5\% were female and the overall mean age was $37.9 \pm 12.1$ years, with $44.6 \%$ of individuals aged between 18 and 34 years, $21.8 \%$ between 35 and 44 years, and $33.7 \%$ aged $\geq 45$ years (Table 1 ). Most participants had Mestizo (67.8\%) or Caucasian skin (23.6\%) (Table 1). In this population, $54.6 \%$ of individuals reported having thin skin, $66.2 \%$ reported dryness, $48.0 \%$ experienced acne, and $44.1 \%$ pigment spots in the past 12 months. Regarding living environment and climate, $85.5 \%$ of individuals were exposed frequently to the sun, $71.1 \%$ to pollution, and $75.9 \%$ to stress (Table 1 ). Almost all individuals (600 out of 606) reported having at least one extrinsic or intrinsic factor as the origin of fragile skin (sun, wind, cold, pollution, humidity, air conditioning, and stress).

Overall, 50.0\% (95\% confidence interval [CI] 45.9\%, $54.1 \%$ ) of participants reported having fragile skin. The rate of fragile skin was not significantly different between skin types $(P=0.4167)$, although $47.5 \%$ of participants $(95 \%$ CI $42.5 \%, 52.4 \%$ ) with Mestizo skin reported fragile skin versus $57.3 \%$ of participants (95\% CI 48.8\%, 65.6\%) with Caucasian skin. The rate of fragile skin was not significantly different between regions ( $P=0.1720)$.

Overall, 136 patients experienced no skin disease and/ or dermatological procedure during the previous 12 months. Of these patients, $29.4 \%$ declared that they had fragile skin. However, among the 470 patients with at least one skin disease and/or who experienced at least one dermatological procedure during the past 12 months, $56.0 \%$ of patients declared that they had fragile skin $(P<0.0001)$.

\section{Analysis according to gender}

There were no differences in sociodemographic characteristics or skin type according to gender. Overall, the perception of fragile skin was significantly higher in female $(58.7 \%)$
Table I Characteristics of study participants

\begin{tabular}{|c|c|c|}
\hline Characteristics & $\begin{array}{l}\text { Mexico } \\
(\mathrm{N}=606)\end{array}$ & $\begin{array}{l}\text { Russia } \\
(\mathrm{N}=604)\end{array}$ \\
\hline \multicolumn{3}{|l|}{ Gender, n (\%) } \\
\hline Male & $294(48.5)$ & $272(45.0)$ \\
\hline Female & $312(5 \mid .5)$ & $332(55.0)$ \\
\hline \multicolumn{3}{|l|}{ Age (years) } \\
\hline Mean \pm SD & $37.9 \pm 12.1$ & $42.4 \pm 12.6$ \\
\hline Range (years), n (\%) & $18-73$ & $18-80$ \\
\hline $18-34$ & $270(44.6)$ & $190(31.5)$ \\
\hline $35-44$ & $132(21.8)$ & III (I8.4) \\
\hline$\geq 45$ & $204(33.7)$ & $303(50.2)$ \\
\hline \multicolumn{3}{|l|}{ Region } \\
\hline \multicolumn{3}{|l|}{ Mexico, n (\%) } \\
\hline Center & $235(38.8)$ & \\
\hline North & $142(23.4)$ & \\
\hline Gulf & $92(15.2)$ & \\
\hline Pacific & 77 (I2.7) & \\
\hline South & $60(9.90)$ & \\
\hline \multicolumn{3}{|l|}{ Russia, n (\%) } \\
\hline Central Federal District & & $169(28.0)$ \\
\hline Southern Federal District & & $92(15.2)$ \\
\hline Northwestern Federal District & & $65(10.8)$ \\
\hline Far Eastern Federal District & & $21(3.5)$ \\
\hline Siberian Federal District & & $77(12.8)$ \\
\hline Ural Federal District & & $62(10.3)$ \\
\hline Volga Federal District & & $118(19.5)$ \\
\hline \multicolumn{3}{|l|}{ Skin type, n (\%) } \\
\hline Mestizo & $4 I I(67.8)$ & $7(1.2)$ \\
\hline Caucasian & $143(23.6)$ & $567(93.9)$ \\
\hline Black & $4(0.7)$ & $\mathrm{I}(0.2)$ \\
\hline Arabic & $8(1.3)$ & $\mathrm{I}(0.2)$ \\
\hline Asian & $7(1.2)$ & $8(1.3)$ \\
\hline Indian & $3(0.5)$ & NA \\
\hline Turkish & $\mathrm{I}(0.2)$ & $5(0.8)$ \\
\hline Mongolian & NA & $5(0.8)$ \\
\hline "I do not want to answer" & $29(4.8)$ & $10(1.7)$ \\
\hline \multicolumn{3}{|l|}{ Living environment and climate, $\mathrm{n}(\%)$} \\
\hline Sun & $518(85.5)$ & $421(69.7)$ \\
\hline Wind & $387(63.9)$ & $484(80.1)$ \\
\hline Cold & $293(48.4)$ & $455(75.3)$ \\
\hline Pollution & $43 I(7 I .1)$ & $365(60.4)$ \\
\hline Humidity & $334(55.1)$ & $247(40.9)$ \\
\hline Air conditioning & $290(47.9)$ & $282(46.7)$ \\
\hline Stress & $460(75.9)$ & $430(7 I .2)$ \\
\hline
\end{tabular}

Abbreviation: NA, not applicable.

than in male $(40.8 \%)$ participants $(P<0.0001)$. Female participants also reported the following skin characteristics more frequently than males: velvety skin in appearance (45.8\% vs $33.7 \%$; $P=0.0023)$, dryness $(72.1 \%$ vs $59.9 \%$; $P=0.0014)$, and tightness $(28.9 \%$ vs $14.3 \% ; P<0.0001)$. In the previous 12 months, females experienced pigment spots $(55.5 \%$ vs $32.0 \% ; P<0.0001)$ and eczema $(24.0 \%$ vs $16.0 \% ; P=0.0135)$ more frequently than males and had dermatological procedures, including peeling (14.4\% vs $7.5 \% ; P=0.0065)$ and lasers $(17.0 \%$ vs $3.4 \% ; P<0.0001)$, 
more frequently. Females were also more frequently exposed to pollution $(74.7 \%$ vs $67.4 \% ; P=0.0465)$ and stress $(81.1 \%$ vs $70.4 \% ; P=0.0021)$.

\section{Analysis according to age category}

There were no differences in sociodemographic characteristics or skin type according to age. There were also no differences in skin characteristics by age, with the exception of other skin characteristics which increased with age (8.9\% [18-34 years] vs $16.7 \%$ [35-44 years] vs $17.7 \%$ $[\geq 45$ years]; $P=0.0109$ ). All skin symptoms decreased with age. With regard to skin diseases, acne decreased with age (66.3\% [18-34 years] vs 47.0\% [35-44 years] vs $24.5 \%$ $[\geq 45$ years]; $P<0.0001)$. Dermabrasion was the only dermatological procedure which differed according to age $(11.9 \%$ [18-34 years] vs $8.3 \%$ [35-44 years] vs 3.4\% [ $\geq 45$ years]; $P=0.0043)$. Participants in the oldest age category ( $\geq 45$ years) were less exposed to cold $(P=0.0005)$, humidity $(P=0.0067)$, and stress $(P=0.015)$.

The rate of fragile skin tended to be higher in the youngest age categories $(53.0 \%$ in the $18-34$ years category and $52.3 \%$ in the $35-44$ years category) compared with the oldest participants $(44.6 \%)$, but the difference did not reach statistical significance $(P=0.1658)$.

\section{Analysis according to fragile skin}

Among the participants with perceived fragile skin, there were no differences in age or skin type according to fragile skin; however, significantly more females than males perceived their skin to be fragile $(60.4 \%$ vs $39.6 \% ; P<0.0001$;
Table 2). Participants with perceived fragile skin reported the following characteristics more frequently than individuals who did not perceive that they had fragile skin:

- Skin appearance: thin (60.7\% vs $48.5 \% ; P=0.0025)$, easily wrinkled (45.2\% vs $22.1 \% ; P<0.0001)$, and transparent (18.5\% vs 9.2\%; $P<0.005)$ (Table 3$)$.

- Skin symptoms: principally dryness (74.6\% vs $57.8 \%$; $P<0.0001)$, redness $(55.1 \%$ vs $23.8 \% ; P<0.0001)$, and itching (49.5\% vs $33.3 \% ; P<0.0001)$ (Table 3 ).

- Skin disease in the past 12 months: principally acne (53.1\% vs $42.9 \% ; P<0.0117)$ and pigment spots $(52.2 \%$ vs $36.0 \% ; P<0.0001$ ) (Table 4 ).

- Dermatological procedures in the past 12 months: principally peeling $(14.5 \%$ vs $7.6 \% ; P=0.0065)$ (Table 4$)$.

- Exposure to stress $(81.2 \%$ vs $70.6 \% ; P=0.0024)$, pollution (77.2\% vs $65.0 \% ; P=0.0009)$, and cold ( $56.8 \%$ vs $39.9 \%$; $P<0.0001$ ) (Table 2).

- Among the 600 patients having at least one extrinsic or intrinsic factor as the origin of fragile skin (sun, wind, cold, pollution, humidity, air conditioning, and stress), $50.2 \%$ of patients declared that they had fragile skin.

\section{Russia}

Among the 604 participants in Russia, 55.0\% were female and the overall mean age was $42.4 \pm 12.6$ years, with $31.5 \%$ of individuals aged between 18 and 34 years, $18.4 \%$ between 35 and 44 years, and $50.2 \%$ aged $\geq 45$ years (Table 1 ). Almost all participants (93.9\%) had Caucasian skin (Table 1). Moreover, $46.2 \%$ of individuals reported having thin skin, $70.0 \%$ reported skin dryness, $53.6 \%$ tightness, and

Table 2 Characteristics of the study population according to fragile skin

\begin{tabular}{|c|c|c|c|c|c|c|}
\hline \multirow[t]{2}{*}{ Characteristics } & \multicolumn{3}{|c|}{ Mexico $(\mathrm{N}=606)$} & \multicolumn{3}{|c|}{ Russia (N=604) } \\
\hline & $\begin{array}{l}\text { Fragile skin } \\
(N=303)\end{array}$ & $\begin{array}{l}\text { No fragile } \\
\text { skin }(N=303)\end{array}$ & $\boldsymbol{P}$-value $\left(\chi^{2}\right)$ & $\begin{array}{l}\text { Fragile skin } \\
(N=277)\end{array}$ & $\begin{array}{l}\text { No fragile } \\
\text { skin }(N=327)\end{array}$ & $\boldsymbol{P}$-value $\left(\chi^{2}\right)$ \\
\hline \multicolumn{7}{|l|}{ Age (years) } \\
\hline $18-34, \mathrm{n}(\%)$ & 143 (47.2) & 127 (4I.9) & 0.1658 & $96(34.7)$ & $94(28.8)$ & 0.1051 \\
\hline $35-44$, n (\%) & $69(22.8)$ & $63(20.8)$ & & $55(19.9)$ & $56(17.1)$ & \\
\hline$\geq 45, \mathrm{n}(\%)$ & $91(30.0)$ & II3 (37.3) & & $126(45.5)$ & $177(54.1)$ & \\
\hline \multicolumn{7}{|l|}{ Gender, n (\%) } \\
\hline Male & $120(39.6)$ & I 74 (57.4) & $<0.0001$ & $82(29.6)$ & $190(58.1)$ & $<0.0001$ \\
\hline Female & $183(60.4)$ & $129(42.6)$ & & $195(70.4)$ & 137 (4I.9) & \\
\hline \multicolumn{7}{|c|}{ Living environment and climate, n (\%) } \\
\hline Sun & $26 I(86.1)$ & $257(84.8)$ & 0.6447 & 197 (7I.I) & $224(68.5)$ & 0.4855 \\
\hline Wind & 204 (67.3) & 183 (60.4) & 0.0758 & $233(84.1)$ & $251(76.8)$ & 0.0239 \\
\hline Cold & $172(56.8)$ & $|2|$ (39.9) & $<0.0001$ & $217(78.3)$ & $238(72.8)$ & 0.1145 \\
\hline Pollution & $234(77.2)$ & $197(65.0)$ & 0.0009 & |8| (65.3) & $184(56.3)$ & $0.023 I$ \\
\hline Humidity & $169(55.8)$ & $165(54.5)$ & 0.7439 & I I 3 (40.8) & I 34 (4I.0) & 0.9634 \\
\hline Air conditioning & $148(48.8)$ & 142 (46.9) & 0.6256 & $152(54.9)$ & 130 (39.8) & 0.0002 \\
\hline Stress & $246(8 I .2)$ & $214(70.6)$ & 0.0024 & $226(8 I .6)$ & $204(62.4)$ & $<0.0001$ \\
\hline
\end{tabular}

Notes: $P$-values shown in bold are those which reached the $5 \%$ significance level. 
Table 3 Skin appearance and symptoms according to fragile skin

\begin{tabular}{|c|c|c|c|c|c|c|}
\hline \multirow[t]{2}{*}{ Skin characteristics } & \multicolumn{2}{|c|}{ Mexico $(\mathrm{N}=606)$} & \multirow[t]{2}{*}{$P$-value $\left(\chi^{2}\right)$} & \multicolumn{2}{|c|}{ Russia $(\mathrm{N}=604)$} & \multirow[t]{2}{*}{$\boldsymbol{P}$-value $\left(\alpha^{2}\right)$} \\
\hline & $\begin{array}{l}\text { Fragile skin } \\
(\mathrm{N}=303)\end{array}$ & $\begin{array}{l}\text { No fragile } \\
\text { skin }(N=303)\end{array}$ & & $\begin{array}{l}\text { Fragile skin } \\
(\mathrm{N}=277)\end{array}$ & $\begin{array}{l}\text { No fragile skin } \\
(\mathrm{N}=327)\end{array}$ & \\
\hline \multicolumn{7}{|l|}{ Skin appearance, $\mathrm{n}(\%)$} \\
\hline Transparent & $56(18.5)$ & $28(9.2)$ & 0.0010 & $88(31.8)$ & $28(8.6)$ & $<0.0001$ \\
\hline Thin & $184(60.7)$ & $147(48.5)$ & 0.0025 & $184(66.4)$ & $95(29.1)$ & $<0.0001$ \\
\hline Easily wrinkled & $137(45.2)$ & $67(22.1)$ & $<0.0001$ & I $33(48.0)$ & $88(26.9)$ & $<0.0001$ \\
\hline Velvety in appearance & $124(40.9)$ & 118 (38.9) & 0.6187 & $119(43.0)$ & $149(45.6)$ & 0.5207 \\
\hline Other skin characteristics & $48(15.8)$ & $34(1 \mathrm{I} .2)$ & 0.0964 & $44(15.9)^{\prime}$ & $57(17.4)$ & 0.6118 \\
\hline \multicolumn{7}{|l|}{ Skin symptoms, n (\%) } \\
\hline Tingling & $117(38.6)$ & $66(21.8)$ & $<0.0001$ & $102(36.8)$ & 75 (22.9) & 0.0002 \\
\hline Warming up sensation & $143(47.2)$ & $116(38.3)$ & 0.0266 & $129(46.6)$ & $118(36.1)$ & 0.0090 \\
\hline Tightness & $94(31.0)$ & $38(12.5)$ & $<0.0001$ & $202(72.9)$ & $122(37.3)$ & $<0.0001$ \\
\hline Itching & $150(49.5)$ & $101(33.3)$ & $<0.0001$ & $126(45.5)$ & $86(26.3)$ & $<0.0001$ \\
\hline Burning & $77(25.4)$ & $30(9.9)$ & $<0.0001$ & $76(27.4)$ & $44(13.5)$ & $<0.0001$ \\
\hline Pain & $50(16.5)$ & $26(8.6)$ & 0.0032 & $56(20.2)$ & $5 I(15.6)$ & 0.1384 \\
\hline Redness & $167(55.1)$ & $72(23.8)$ & $<0.0001$ & $175(63.2)$ & $119(36.4)$ & $<0.0001$ \\
\hline Dryness & $226(74.6)$ & $175(57.8)$ & $<0.0001$ & $239(86.3)$ & $184(56.3)$ & $<0.0001$ \\
\hline
\end{tabular}

Notes: $P$-values shown in bold are those which reached the $5 \%$ significance level.

Table 4 Skin diseases and dermatologic procedures according to fragile skin

\begin{tabular}{|c|c|c|c|c|c|c|}
\hline \multirow{2}{*}{$\begin{array}{l}\text { Skin disease/ } \\
\text { dermatologic procedure }\end{array}$} & \multicolumn{2}{|c|}{ Mexico $(\mathrm{N}=606)$} & \multirow[t]{2}{*}{$\boldsymbol{P}$-value $\left(\chi^{2}\right)$} & \multicolumn{2}{|c|}{ Russia $(\mathrm{N}=604)$} & \multirow[t]{2}{*}{$P$-value } \\
\hline & $\begin{array}{l}\text { Fragile skin } \\
(\mathrm{N}=303)\end{array}$ & $\begin{array}{l}\text { No fragile } \\
\text { skin }(N=303)\end{array}$ & & $\begin{array}{l}\text { Fragile skin } \\
(\mathrm{N}=277)\end{array}$ & $\begin{array}{l}\text { No fragile skin } \\
(\mathrm{N}=327)\end{array}$ & \\
\hline \multicolumn{7}{|l|}{ Skin disease, $\mathrm{n}(\%)$} \\
\hline Acne & $161(53.1)$ & $130(42.9)$ & 0.0117 & $68(24.6)$ & $39(11.9)$ & $<0.0001(C)$ \\
\hline Eczema & $85(28.1)$ & $37(12.2)$ & $<0.0001$ & $28(10.1)$ & $8(2.5)$ & $<0.0001$ (C) \\
\hline Psoriasis & $17(5.6)$ & $8(2.6)$ & 0.0660 & $22(7.9)$ & $13(4.0)$ & $0.0376(C)$ \\
\hline $\begin{array}{l}\text { Pigment spots (pale spots, } \\
\text { brown spots) }\end{array}$ & $158(52.2)$ & $109(36.0)$ & $<0.0001$ & $118(42.6)$ & $68(20.8)$ & $<0.0001(C)$ \\
\hline Other skin diseases & $23(7.6)$ & $15(5.0)$ & 0.1801 & $42(15.2)$ & $30(9.2)$ & $0.0236(C)$ \\
\hline \multicolumn{7}{|c|}{ Dermatologic procedures, n (\%) } \\
\hline Peeling & $44(14.5)$ & $23(7.6)$ & 0.0065 & $83(30.0)$ & $33(10.1)$ & $<0.000$ I (C) \\
\hline Lasers & $40(13.2)$ & $23(7.6)$ & 0.0237 & $26(9.4)$ & $15(4.6)$ & $0.0195(C)$ \\
\hline Dermabrasion & $32(10.6)$ & $18(5.9)$ & 0.0387 & $18(6.5)$ & $2(0.6)$ & $<0.0001$ (F) \\
\hline $\begin{array}{l}\text { Dermatological surgery } \\
\text { (resection, curettage) }\end{array}$ & $17(5.6)$ & $7(2.3)$ & 0.0373 & $6(2.2)$ & $6(1.8)$ & $0.7713(\mathrm{C})$ \\
\hline Wrinkle filling injections & $10(3.3)$ & $8(2.6)$ & 0.6322 & $17(6.1)$ & $7(2.1)$ & $0.0122(C)$ \\
\hline $\begin{array}{l}\text { Other dermatological } \\
\text { procedure }\end{array}$ & $18(5.9)$ & $19(6.3)$ & 0.8653 & $29(10.5)$ & $12(3.7)$ & 0.0009 (C) \\
\hline
\end{tabular}

Notes: $P$-values shown in bold are those which reached the $5 \%$ significance level.

Abbreviations: $\mathrm{C}, \chi^{2}$; F, Fisher's test.

$48.7 \%$ redness. In addition, $30.8 \%$ of individuals experienced pigment spots and $19.2 \%$ underwent peeling in the past 12 months. With regard to living environment and climate, $80.1 \%$ of individuals were exposed frequently to wind, $75.3 \%$ to cold, $71.2 \%$ to stress, and $69.7 \%$ to sun (Table 1). Almost all individuals (576 out of 604) reported having at least one extrinsic or intrinsic factor as the origin of fragile skin (sun, wind, cold, pollution, humidity, air conditioning, and stress).
In this population, $45.9 \%$ ( $95 \%$ CI $41.8 \%, 49.9 \%)$ of individuals reported having fragile skin. There was no relevant difference in the rate of fragile skin between regions $(P=0.4386)$.

Overall, 251 patients experienced no skin disease and/ or dermatological procedure during the previous 12 months. Of these patients, $27.1 \%$ declared that they had fragile skin. However, among the 353 patients with at least one skin disease and/or who experienced at least one dermatological 
procedure during the past 12 months, $59.2 \%$ of patients declared that they had fragile skin $(P<0.0001)$.

\section{Analysis according to gender}

There were no differences in sociodemographic characteristics or skin type according to gender. Overall, the perception of fragile skin was significantly higher in females than in males $(58.7 \%$ vs $30.2 \% ; P<0.0001)$. A higher proportion of female participants also reported having thin skin $(57.5 \%$ vs $32.4 \% ; P<0.0001)$ or velvety skin $(54.2 \%$ vs $32.4 \%$; $P<0.0001)$, and skin symptoms, including dryness $(83.7 \%$ vs $53.3 \% ; P<0.0001)$ and tightness $(69.3 \%$ vs $34.6 \%$; $P<0.0001)$. Females also experienced pigment spots $(42.8 \%$ vs $16.2 \% ; P<0.0001)$ and acne $(23.5 \%$ vs $10.7 \% ; P<0.0001)$ more frequently than males and more frequently underwent dermatological procedures during the previous 12 months, including peeling (30.1\% vs 5.9\%; $P<0.0001)$. Females were also exposed to pollution ( $65.4 \%$ vs $54.4 \% ; P=0.0062)$ and stress $(79.8 \%$ vs $60.7 \% ; P<0.0001)$ more frequently than male participants.

\section{Analysis according to age category}

There were no differences in sociodemographic characteristics, skin type, skin characteristics, or living environment and climate, according to age. With regard to skin symptoms, warming up sensation decreased with age $(46.8 \%$ [18-34 years] vs $44.1 \%$ [ $35-44$ years] vs $36.0 \%$ [ $\geq 45$ years]; $P=0.0428)$. With regard to skin diseases, acne decreased with age (32.1\% [18-34 years] vs 22.5\% [35-44 years] vs $6.9 \%$ [ $\geq 45$ years]; $P<0.0001)$, whereas pigment spots increased with age $(20.5 \%$ [ $18-34$ years] vs $36.0 \%$ [35-44 years] vs $35.3 \%$ [ $\geq 45$ years]; $P=0.001$ ). Peeling was the only dermatological procedure that differed significantly according to age $(22.6 \%$ [18-34 years] vs $27.9 \%$ [35-44 years] vs $13.9 \%[\geq 45$ years]; $P=0.002)$. The rate of fragile skin tended to be higher in the youngest age categories $(50.5 \%$ in the 18-34 years category and $49.5 \%$ in the $35-44$ years category) compared with the oldest participants $(41.6 \%)$, but the difference did not reach statistical significance $(P=0.1051)$.

\section{Analysis according to fragile skin}

Among the participants with perceived fragile skin, there were no differences in age or skin type according to fragile skin; however, significantly more females than males perceived their skin to be fragile $(70.4 \%$ vs $29.6 \% ; P<0.0001$; Table 2). Individuals with perceived fragile skin reported the following characteristics more frequently than individuals who did not perceive that they had fragile skin:

- Skin appearance: thin (66.4\% vs $29.1 \% ; P<0.0001)$, easily wrinkled (48.0\% vs $26.9 \% ; P<0.0001)$, and transparent (31.8\% vs $8.6 \% ; P<0.0001)$ (Table 3$)$.

- Skin symptoms: principally dryness $(86.3 \%$ vs $56.3 \%$; $P<0.0001)$, tightness $(72.9 \%$ vs $37.3 \% ; P<0.0001)$, and redness $(63.2 \%$ vs $36.4 \% ; P<0.0001)$ (Table 3$)$.

- Skin disease in the past 12 months: principally pigment spots $(42.6 \%$ vs $20.8 \% ; P<0.0001)$ and acne $(24.6 \%$ vs $11.9 \% ; P<0.0001$ ) (Table 4$)$.

- Dermatological procedures in the past 12 months: principally peeling $(30.0 \%$ vs $10.1 \% ; P<0.0001)$ (Table 4$)$.

- Exposure to wind ( $84.1 \%$ vs $76.8 \% ; P=0.0239$ ), stress (81.6\% vs $62.4 \% ; P<0.0001)$, pollution $(65.3 \%$ vs $56.3 \%$; $P=0.0231)$, and air conditioning $(54.9 \%$ vs $39.8 \%$; $P=0.0002$ ) (Table 2).

- Among the 576 patients having at least one extrinsic or intrinsic factor as the origin of fragile skin (sun, wind, cold, pollution, humidity, air conditioning, and stress), $46.7 \%$ of patients declared that they had fragile skin.

\section{Discussion}

The current study, reporting rich data from two identical Internet-based surveys conducted in Mexico and Russia, provides a valuable insight into the prevalence of perceived fragile skin and skin characteristics associated with perceived fragile skin, in two distinct populations totaling more than 1,200 adults.

Despite the wide geographic separation between the two populations, the majority of findings from the surveys in Mexico and Russia revealed clear similarities with regard to the perception of fragile skin. In Mexico and Russia, the prevalence of perceived fragile skin was significantly higher in females than in males. The principal skin appearance characteristics reported by individuals with perceived fragile skin were thin, easily wrinkled, and transparent; the main skin symptoms were dryness, redness, and/or itching $(\geq 50 \%$ of individuals in Mexico), and dryness, tightness, and/or redness ( $>60 \%$ of individuals in Russia). Individuals with perceived fragile skin in both countries had experienced skin disease in the past 12 months, mainly pigment spots and acne, had undergone a dermatological procedure in the past 12 months, principally peeling or laser, and reported being exposed to stress ( $>80 \%$ of individuals in both surveys). The latter observation is particularly notable given the growing body 
of evidence regarding the significant role that psychosocial stress plays in the exacerbation of skin disease. ${ }^{7,10}$

The prevalence of perceived fragile skin in the current Internet-based study (50.0\% [Mexico] and 45.9\% [Russia]) was consistent between the two distinct populations but differed slightly from that reported in a previously published telephone-based survey. ${ }^{9}$ The previous survey, conducted in 4,913 individuals aged 15-65 years in France, Spain, Sweden, Japan, and the USA, reported perceived fragile skin in $24.4 \%, 29.7 \%, 52.7 \%$, and $42.2 \%$ of participants with Caucasian South, Caucasian North, Asian, and Black skin, respectively. ${ }^{9}$ There may be multiple reasons to explain these differences based upon the four classification categories of fragile skin proposed by Stalder et al. ${ }^{3}$ The prevalence rates in the current study, 50\% in Mexico (mainly Mestizo skin) and $45.9 \%$ in Russia (mainly Caucasian), are at the high end of the range reported in the previous study. These high rates may possibly reflect the fact that nearly all patients surveyed in Mexico (600/606) and Russia (576/604) $)^{11}$ declared having at least one intrinsic or extrinsic factor (sun, wind, cold, pollution, humidity, air conditioning, or stress) as the origin of fragile skin. Other potential contributing factors include the presence of concomitant skin diseases such as acne or eczema, or the need to undergo dermatological procedures such as peeling, laser therapy, or dermabrasion. However, the relative risks of these various factors remain to be elucidated.

At the molecular level, fragile skin associated with acne, rosacea, and reactive skin has been linked to innate immunity dysfunction via inflammasome pathway activation. ${ }^{12,13}$ Therefore, variables originating from individuals, as well as exogenous factors, have an important influence on epidermal barrier parameters. ${ }^{14}$ For example, skin type, regardless of race and gender, has previously been shown to influence epidermal permeability barrier function, with darkly pigmented skin displaying a more resistant barrier that recovers more rapidly after perturbation than lighter pigmented skin. ${ }^{15}$ However, further studies are required to assess whether differences in the perception of fragile skin in various regions of the world reflect differences in epidermal permeability barrier function in individuals.

Within the wider concept of fragile skin, there is a reactive skin entity (also referred to as sensitive skin), which is a complex dermatological condition defined by the occurrence of unpleasant sensations (eg, stinging, burning, pain, pruritus, and tingling) in response to stimuli that normally should not provoke such sensations and that cannot be explained by lesions attributable to skin disease. ${ }^{3,16} \mathrm{~A}$ recent study has shown that the pathophysiology of skin sensitivity resembles that of neuropathic pruritus within the context of small fiber neuropathy, and that environmental factors may alter skin innervation. ${ }^{17}$ Reactive skin can appear normal or accompanied by erythema, can affect all body locations, particularly the face, and may worsen in the presence of a simultaneous dermatosis. ${ }^{16}$

Although there are currently limited data on the perceived prevalence of fragile skin in general adult populations, previous studies have evaluated the prevalence of reactive (sensitive) skin in individuals from a range of different populations, including the UK, ${ }^{18}$ France, ${ }^{19}$ Europe,${ }^{20}$ Japan, ${ }^{21}$ Brazil and Russia, ${ }^{22}$ and the USA. ${ }^{23}$ Individuals reported a high prevalence of perceived reactive skin in these studies and, in general, reactive skin appeared to be reported more frequently in females than in males. ${ }^{24}$ Although it is important to acknowledge differences between reactive skin and fragile skin, the findings from our study show that a similarly substantial proportion of the general adult populations in Mexico and Russia has perceived fragile skin, and that it occurred in significantly more females than males.

Although Internet-based surveys represent a popular method of survey data collection, self-selection and population coverage potentially limit their representativeness. ${ }^{25,26} \mathrm{In}$ the current study, individuals from a large panel who were representative of the Mexican and Russian populations were invited by email to participate in the Internet-based surveys. Participants, selected using the quota method according to gender, age, and geographical region, were requested to complete the questionnaire online. Consequently, data are representative of the adult Mexican and Russian populations, but only according to the quota criteria. Overall, $15.8 \%$ and $10.4 \%$ of invited participants in Mexico and Russia, respectively, had incomplete questionnaires. However, since only participants with a complete questionnaire were analyzed, the study had a relatively low risk of bias regarding representativeness.

Data from the current web-based surveys showed that the difference in the rate of fragile skin was not significantly different between age categories (although there was a tendency for a higher prevalence in the youngest age categories), contrary to the findings from the survey conducted by telephone interview. ${ }^{9}$ However, this study confirmed the higher prevalence of perceived fragile skin among females compared with males in Mexico and Russia.

In summary, this study shows that, regardless of skin type, a substantial proportion of the general population of Mexico and Russia perceives fragile skin. Moreover, in both 
populations, fragile skin was perceived more frequently in women. These findings add to those reported previously from other geographical locations and should assist dermatologists to extend their understanding and management of individuals with perceived fragile skin.

\section{Acknowledgments}

The authors thank David P. Figgitt PhD, Content Ed Net, for providing medical writing assistance, with funding from Pierre Fabre S.A.

\section{Disclosure}

Dr. Jorge Ocampo-Candiani has served as a principal investigator for Abbott Laboratories, Anacor Pharmaceuticals, Inc., Bayer Pharmaceuticals, Bristol-Myers Squibb, Galderma Laboratorios, LP, GlaxoSmithKline, Janssen-Ortho Inc., Merz Aesthetics, Novartis Pharmaceuticals Corp., Pfizer, Schering-Plough Healthcare Products, and Stiefel (a GSK company); and has served as a speaker and on an advisory board for Leo Pharma Inc., Merz Aesthetics, Procter \& Gamble Company, and Stiefel (a GSK company), and as a consultant for Pierre Fabre Dermo-Cosmétique. Professor Nikolay Murashkin is a consultant for Pierre Fabre DermoCosmétique. Professor Pierre Wolkenstein is a consultant for Pierre Fabre Dermo-Cosmétique; Dr. Markéta Saint Aroman is an employee of Pierre Fabre Dermo-Cosmétique, Laboratoires A-DERMA; Asmaa Zkik is an employee of Pierre Fabre S.A.

\section{References}

1. Jensen JM, Proksch E. The skin's barrier. G Ital Dermatol Venereol. 2009;144(6):689-700.

2. Baroni A, Buommino E, De Gregorio V, Ruocco E, Ruocco V, Wolf R. Structure and function of the epidermis related to barrier properties. Clin Dermatol. 2012;30(3):257-262.

3. Stalder JF, Tennstedt D, Deleuran M, et al. Fragility of epidermis and its consequence in dermatology. J Eur Acad Dermatol Venereol. 2014;28 (Suppl 4):1-18.

4. Blume-Peytavi U, Tan J, Tennstedt D, et al. Fragility of epidermis in newborns, children and adolescents. J Eur Acad Dermatol Venereol. 2016;30 (Suppl 4):3-56.

5. McLeod RP, Elias PM, Eichenfield LF, Fowler JF Jr, Horowitz P. A lifetime of well skin care: practical recommendations for clinicians and patients. Semin Cutan Med Surg. 2013;32 (2 Suppl 2):S28-S29.
6. Blume-Peytavi U, Hauser M, Stamatas GN, Pathirana D, Garcia Bartels N. Skin care practices for newborns and infants: review of the clinical evidence for best practices. Pediatr Dermatol. 2012;29(1):1-14.

7. Hunter HJ, Momen SE, Kleyn CE. The impact of psychosocial stress on healthy skin. Clin Exp Dermatol. 2015;40(5):540-546.

8. Proksch E, Brandner JM, Jensen JM. The skin: an indispensable barrier. Exp Dermatol. 2008;17(12):1063-1072.

9. Haftek M, Coutanceau C, Taïeb C. Epidemiology of "fragile skin": results from a survey of different skin types. Clin Cosmet Investig Dermatol. 2013;6:289-294.

10. Reich A, Wójcik-Maciejewicz A, Slominski AT. Stress and the skin. $G$ Ital Dermatol Venereol. 2010;145(2):213-219.

11. Saint Aroman M, Murashkin N, Zkik A, Chalem Y, Wolkenstein P. Prevalence of fragile skin in Russia. Poster presented at: 9th World Dermatology and Venereology, Congress; Manchester, UK; 10-11 October 2016.

12. Fabbrocini G, Galliano M-F, Aries M-F, et al. Fragility of the epidermis, a common pathophysiological mechanism of acne vulgaris, rosacea and reactive skin involving inflammasome activation. Inflamm Cell Signal. 2015;2:e909.

13. Fabbrocini G, Saint Aroman M. Cosmeceuticals based on Rhealba ${ }^{\circledR}$ Oat plantlet extract for the treatment of acne vulgaris. J Eur Acad Dermatol Venereol. 2014;28(Suppl 6):1-6.

14. Darlenski R, Fluhr JW. Influence of skin type, race, sex, and anatomic location on epidermal barrier function. Clin Dermatol. 2012;30(3):269-273.

15. Reed JT, Ghadially R, Elias PM. Skin type, but neither race nor gender, influence epidermal permeability barrier function. Arch Dermatol. 1995;131(10):1134-1138

16. Misery L, Ständer S, Szepietowski JC, et al. Definition of sensitive skin: an expert position paper from the special interest group on sensitive skin of the International Forum for the Study of Itch. Acta Derm Venereol. 2017;97(1):4-6.

17. Buhé V, Vié K, Guéré C, et al. Pathophysiological study of sensitive skin. Acta Derm Venereol. 2016;96(3):314-318.

18. Willis CM, Shaw S, De Lacharrière $\mathrm{O}$, et al. Sensitive skin: an epidemiological study. Br J Dermatol. 2001;145(2):258-263.

19. Misery L, Myon E, Martin N, Verrière F, Nocera T, Taieb C. Peaux sensibles en France : approche épidémiologique. [Sensitive skin in France: an epidemiological approach]. Ann Dermatol Venereol. 2005;132(5): 425-429. French.

20. Misery L, Boussetta S, Nocera T, Perez-Cullell N, Taieb C. Sensitive skin in Europe. J Eur Acad Dermatol Venereol. 2009;23(4):376-381.

21. Kamide R, Misery L, Perez-Cullell N, Sibaud V, Taïeb C. Sensitive skin evaluation in the Japanese population. J Dermatol. 2013;40(3):177-181.

22. Taieb C, Auges M, Georgescu V, Perez Cullell N, Miséry L. Sensitive skin in Brazil and Russia: an epidemiological and comparative approach. Eur J Dermatol. 2014;24(3):372-376.

23. Misery L, Sibaud V, Merial-Kieny C, Taieb C. Sensitive skin in the American population: prevalence, clinical data, and role of the dermatologist. Int J Dermatol. 2011;50(8):961-967.

24. Misery L, Loser K, Ständer S. Sensitive skin. J Eur Acad Dermatol Venereol. 2016;30(Suppl 1):2-8.

25. Bethlehem J. Selection bias in web surveys. Internat Statist Rev. 2010;78(2):161-188.

26. Couper MP. The future of modes of data collection. Public Opin Q. 2011;75(5):889-908.
Clinical, Cosmetic and Investigational Dermatology

\section{Publish your work in this journal}

Clinical, Cosmetic and Investigational Dermatology is an international, peer-reviewed, open access, online journal that focuses on the latest clinical and experimental research in all aspects of skin disease and cosmetic interventions. This journal is included on PubMed. The manuscript management system is completely online

\section{Dovepress}

and includes a very quick and fair peer-review system, which is all easy to use. Visit http://www.dovepress.com/testimonials.php to read real quotes from published authors 